\title{
Sequência didática e comunidades tradicionais: análise do letramento científico crítico
}

\author{
Geane Machado Araujo' \\ Universidade Estadual de Feira de Santana / Univeversidade Federal da Bahia \\ Geilsa Costa Santos Baptista ${ }^{2}$ iD \\ Universidade Estadual de Feira de Santana
}

Camila Cunha ${ }^{3}$

Univeversidade Federal da Bahia

\section{Dossiê | Dossier | Dosier \\ DOI do artigo: 10.22481/odeere.v6i01.9790 \\ RESUMO}

Apresentamos os resultados de uma pesquisa qualitativa, envolvendo a elaboração e aplicação de uma sequência didática numa escola pública do Estado da Bahia, Brasil, localizada no contexto de comunidades tradicionais. Os dados foram coletados após a aplicação de uma sequência didática que gerou a oportunidade de tomada de decisão por parte dos estudantes diante de uma problemática dos transgênicos, relacionada ao seu cotidiano. Os resultados mostram os níveis e estágios de letramento científico alcançados por cada grupo e foram analisados a partir do modelo proposto por Conrado (2017). Os grupos apresentaram dificuldades argumentativas, no entanto, as decisões apresentadas demonstram o exercício da criticidade, importante para as tomadas de decisões reais em seu cotidiano. Dessa forma, o presente trabalho permitiu realizar reflexões sobre o que pode ser melhorado na sequência didática no que tange a sua abordagem, visando ampliar os níveis e estágios de letramento alcançados pelos estudantes e abrindo margem para trabalhos futuros contendo ajustes que contribuam para o desenvolvimento da criticidade por parte dos estudantes.

Palavras-chave: letramento científico, questões sociocientíficas.

\section{Submetido em: 30/10/2021 | Aceito em: 24/11/2021}

Teaching sequence and traditional communities: analysis of critical scientific literacy

ABSTRACT

We present the results of a qualitative research, involving the elaboration and application of a didactic sequence in a public school in the State of Bahia, Brazil, located in the context of a

1 Graduada em Ciências Biológicas Licenciatura pela Universidade Estadual de Feira de Santana, Mestranda em Ensino, Filosofia e História das Ciências pela Universidade Federal da Bahia. Atualmente é professora da rede particular de ensino e participante do Grupo de pesquisa Investigações em Etnobiologia e Ensino de Ciências (GIEEC). E-mail: geanemachadoaravjo@gmail.com

2 Possui graduação em Licenciatura em Ciências Biológicas pela Universidade Estadual de Feira de Santana (1995), Especialização em Saúde Aplicada ao Ensino de Biologia pela Universidade Federal da Bahia (2000), Mestrado em Ensino, Filosofia e História das Ciências pela Universidade Federal da Bahia (2007) e Doutorado em Ensino, Filosofia e História das Ciências pela Universidade Federal da Bahia (2012), com estágio na Universidade do Minho, Portugal. Participa como membro da Associação Brasileira de Pesquisa em Educação em Ciências (ABRAPEC), da Sociedade Brasileira de Etnobiologia e Etnoecologia (SBBE) e da Red Latinoamericana por la Defensa del Patrimonio Biocultural. É professora Titular no Departamento de Educação da Universidade Estadual de Feira de Santana-BA e no Programa de Pós-Graduação em Ensino, Filosofia e História das Ciências (UFBAUEFS). Fundadora e coordenadora do Grupo de Investigações em Etnobiologia e Ensino de Ciências (GIEEC-UEFS). E-mail: geilsabaptista@gmail.com

3 Graduada em Ciências Biológicas Licenciatura pela Universidade Federal de Sergipe, Mestre em Ensino de Ciências e Matemática (PPGECIMA/UFS) e doutoranda no Programa de Pós-graduação em Ensino, Filosofia e História das Ciências (PPGEFHC/UFBA/UEFS) da Universidade Federal da Bahia e Universidade Estadual de Feira de Santana. Atualmente é professora substituta do Departamento de Educação da Universidade Federal da Bahia e Membro do Grupo de Investigações em Etnobiologia e Ensino de Ciências (GIEEC/UEFS). E-mail: cunhacamila17@gmail.com 
traditional community. Data were collected after the application of a didactic sequence that generated the opportunity for decision-making by the students in face of a problem of transgenics, directly related to their daily lives. The results show the levels and stages of scientific literacy achieved by each group and were analyzed using the model proposed by Conrado (2017). The groups presented argumentative difficulties, however, the decisions presented demonstrate the exercise of criticality, which is important for real decision-making in their daily lives. Thus, the present work allowed for reflections on what can be improved in the didactic sequence regarding its approach, aiming to expand the literacy levels and stages reached by the students and opening room for future work containing adjustments that contribute to the development of the criticality on the part of students.

Keywords: scientific literacy, socio-scientific issues.

\section{INTRODUÇÃO}

A maioria das sociedades ao redor do mundo é marcada pela presença dos avanços científicos e tecnológicos que impactam todas as formas de vida, sejam elas humanas ou não. Estar no mundo atualmente significa tomar decisões diante de situações diversas, especialmente ambientais, o que exige uma escolarização que consiga fornecer aos cidadãos o suficiente para intervir e se posicionar no mundo de maneira coerente e informada, ou seja, de modo a amparar-se nas explicações científicas para decidir sobre situações em que apenas seus conhecimentos prévios não thes dão suporte. Nesse sentido, e partindo da compreensão de que a ciência atua principalmente nas explicações sobre o mundo, considera-se necessário que os estudantes estejam preparados para participar e contribuir para as melhorias no mundo (VIEIRA; VIEIRA, 2014), por meio de reflexões críticas sobre diferentes temáticas.

Levando em consideração que a ciência é uma prática social, entendida como um produto do seu tempo e lugar estando inserida em um contexto social, político e econômico, entende-se que a ciência é influenciada pelo seu contexto sociocultural. Desse modo, é importante que os estudantes tenham um olhar crítico para que possam compreender como a ciência e a tecnologia são influenciadas por determinados interesses e como as normas e valores da prática científica são geralmente subordinados aos interesses comerciais, para que a partir daí possam ser capazes de questionar o que pode ser modificado para alcançar uma sociedade mais justa (HODSON, 2018). Considerando a natureza do conhecimento científico, o ensino de ciências não pode reforçar a sua neutralidade, mas realizar a contextualização através da discussão social desse conhecimento, pois quando os conteúdos científicos são contextualizados passam a dar significado aos estudantes (SANTOS, 2007). 
Essa perspectiva de compreender a ciência e usá-la em favor da tomada de decisões diante de situações diversas, especialmente nas sociedades científica e tecnologicamente influenciadas, é conhecida como letramento científico. Segundo Hodson $(2004,2011)$ o letramento científico crítico envolve o reconhecimento das relações entre ciência, tecnologia, sociedade e ambiente, da influência dos interesses científicos e tecnológicos, além da capacidade de abordagens críticas que envolvam tomada de decisão. Assim, uma prática pedagógica voltada para a promoção do letramento objetiva mostrar caminhos que proporcionem desenvolvimento crítico para a tomada de decisões em questões sociais (SOCOLOSKl, 2011).

Para que isso aconteça é necessário superar o modelo atual de ensino nas escolas através da inserção de três aspectos importantes apresentados por Santos (2007): a natureza da ciência, a linguagem da ciência, e os aspectos sociocientíficos. Assim, os estudantes aprenderão a questionar e tomar decisões utilizando argumentos científicos, sabendo-se que, é preciso problematizar modelos de desenvolvimento científico e tecnológico, superando a visão cientificista, na qual o conhecimento científico-tecnológico é visto como superior (SANTOS, 2008).

Alguns estudos reforçam essa realidade ao apresentarem em seus resultados a dificuldade em que os estudantes têm em utilizar o conhecimento científico para tomar decisões em situações cotidianas, além do entendimento sobre determinados temas próximos a sua realidade baseando-se em discussões midiáticas (SOUZA, FARIAS 2011; PEDRANCINI et al., 2008). A partir desse cenário, e com base em Pedrancini e seus colaboradores (2008) percebe-se que os conhecimentos ensinados na escola não têm possibilitado aos estudantes o entendimento da realidade atual que envolve a ciência, o pensar, falar e agir científico. Sendo necessária uma educação que possibilite aos estudantes a compreensão de conhecimentos científicos e, com base neles, a tomada de decisão consciente diante de problemas enfrentados (PEDRANCINI et al., 2008).

Entendemos que essa premissa se faz ainda mais importante para as comunidades tradicionais, visto que elas "[...] ainda vivem em contato direto com a natureza e possuem uma estreita dependência desta para a manutenção do seu modo de vida" (SILVA; BAPTISTA, 2018, p. 95). Segundo Diegues e Arruda (2001), as comunidades tradicionais são aquelas formadas por grupos humanos que tem uma relação muito próxima com a natureza e compartilham entre si um modo 
específico de vida. Essa relação com a natureza em prol da subsistência produz conhecimentos que são locais e, em alguns casos, não conseguem dar conta dos seus problemas sociais e ambientais (BAPTISTA, 2007).

Contudo, o ensino formal ainda tem apresentado a ciência e a tecnologia como conhecimento fixo que deve ser memorizado. Isto pode explicar as dificuldades vivenciadas pelos estudantes no uso do conhecimento científico, especificamente no que tange as problemáticas controversas, como é o caso das Questões Sociocientíficas (QSC). Estas podem ser compreendidas como temáticas que abrangem controvérsias sobre questões sociais que estão relacionados com o conhecimento científico e têm grande impacto na sociedade, e, em geral são discutidos pela mídia (PÉREZ, 2012).

Diante dessa realidade entendemos a importância de se trabalhar o ensino baseado na perspectiva educacional Ciência, Tecnologia, Sociedade e Ambiente (CTSA) que objetiva a emancipação do sujeito ao permitir que ele problematize a ciência, sendo uma forma de incluir as implicações sociais, políticas, cultural, ética e ambiental para compreensão do conhecimento científico como processo histórico e humano influenciado por vários interesses e ideologias, e promover uma educação que permita a compreensão do funcionamento da ciência na sociedade e a forma pela qual ela influencia o nosso relacionamento com a sociedade e a natureza (PÉREZ, 2012).

O ensino com ênfase nessa perspectiva associada às questões sociocientíficas consiste em uma oportunidade para a aproximação das reais condições de produção da ciência e das suas relações com a tecnologia, com a sociedade e com o meio ambiente a serem trabalhos na sala de aula (SILVA; CARVALHO, 2007). Optamos assim pelo uso da temática sobre transgênicos em nossa sequência didática por entender a partir dos autores já citados que é um tema controverso, pois, resulta em divergência de opiniões acerca da sua segura utilização e comercialização, possibilitando a compreensão de que não há verdade absoluta nem neutralidade na ciência. Para que seja possível um ensino desta maneira é importante que a prática pedagógica seja pautada nas relações dialógicas, sabendo-se que o diálogo na sala de aula é um momento de reflexão dos indivíduos baseado na criticidade que ocorre a partir da troca de ideias entre professor e estudante (FREIRE, 1987). É nesse contexto que propomos uma sequência didática que utilize as dimensões conceituais, procedimentais e 
atitudinais dos conteúdos (ZABALA, 1998), integrados a uma abordagem CTSA associada ao uso de QSC (CONRADO, NUNES-NETO, 2018) como forma de promover o letramento científico em comunidades tradicionais.

Destacamos assim, que o presente trabalho é parte dos resultados de uma pesquisa mais ampla realizada para a conclusão de curso da primeira autora, e tem por objetivo apresentar os níveis e estágios de letramento científico alcançados pelos estudantes de comunidades tradicionais agrícolas após a aplicação de uma sequência didática.

\section{PERCURSO METODOLÓGICO}

\section{Abordagem da pesquisa e realidade escolar}

Neste trabalho, utilizamos uma abordagem qualitativa (CRESWELL, 2010), apresentamos e discutimos a aplicação de uma sequência didática contendo uma QSC para estudantes da $3^{a}$ série do Ensino Médio de uma escola pública inserida no contexto de comunidades tradicionais da Bahia (Aprovações CONSEPE-UEFS $n^{\circ}$ 097/2018; SisGen no AB1A096 e CEP-UEFS $n^{\circ}$ 2.471.094/2018). Participaram dessa pesquisa 21 estudantes entre homens e mulheres, agricultores e não agricultores, com idades entre 15 e 20 anos que estavam regularmente matriculados no ano letivo de 2019.

A escola é localizada no Retiro, distrito de Coração de Maria - Bahia, onde optamos por trabalhar e desenvolver esta pesquisa. Consideramos a necessidade de abordagens com a temática da transgenia nesta realidade uma vez que, segundo Baptista (2007), a maioria da população do município de Coração de Maria reside na zona rural e são agricultores. Segundo a professora colaboradora este é um distrito rural onde a maioria da população estudantil consiste em trabalhadores rurais e ou filhos de trabalhadores rurais, que de alguma maneira ajudam suas famílias na agricultura. Por isso optamos pela inserção do conhecimento sobre alimentos e sementes transgênicas para que os estudantes dessas comunidades tenham acesso a informações científicas com criticidade que possam auxiliar em suas decisões a partir das necessidades existentes no contexto sociocultural agrícola onde vivem. 


\section{Sequência didática}

A sequência didática é "um conjunto de atividades ordenadas, estruturadas e articuladas para a realização de certos objetivos educacionais" (ZABALA, 1998, p.18), que inclui planejamento, aplicação e avaliação como aspectos para uma intervenção reflexiva. A partir dessa visão elaboramos uma sequência didática sobre os transgênicos a partir da perspectiva educacional CTSA, incluindo um caso de QSC tendo como principal objetivo proporcionar aos estudantes o contato com o conhecimento cientifico e a partir daí gerar situações que contribuam para a tomada de decisões que envolvam uma problemática sobre esse tema.

Utilizamos a proposta de Conrado e El-Hani (2018) para estruturar uma abordagem no ensino de ciências a partir da educação CTSA organizada com três elementos: um caso de QSC, questões norteadoras, e objetivos de aprendizagem elaborados a partir de uma concepção ampliada dos conteúdos para o ensino de biologia, visando proporcionar a aprendizagem de dimensões conceituais, procedimentais e atitudinais (CPA). Associada a esses três elementos, também foram consideradas as três fases para trabalhar uma QSC propostas por Hodson (2011), são elas: a modelagem, na qual o professor vai explicar a abordagem e orientar para alcançar os objetivos; a prática guiada, em que o professor auxilia os estudantes na realização das atividades; e a aplicação, que consiste na realização das atividades por parte dos estudantes sem a ajuda do professor para a resolução do caso. Cabe destacar que, adaptamos essas fases e utilizamos apenas a aplicação, dado o fato de que nos foi cedido pela professora colaboradora apenas três encontros, totalizando pouco tempo para o desenvolvimento dessa abordagem e o contato entre pesquisadora e sujeitos participantes.

Por fim, a sequência didática foi validada por meio da apresentação e discussão no Grupo de Investigação em Etnobiologia e Ensino de Ciências (GIEEC) do qual fazem parte as autoras deste trabalho, com intuito de contribuir para sua construção. Segundo Paiva et al. (2017), a validação é um instrumento relevante na realização de ajustes da pesquisa, por meio da análise dos elementos. Como resultado desta colaboração elaboramos uma sequência didática intitulada por "Os transgênicos e suas implicações socioambientais". A seguir apresentamos a QSC e logo depois os três encontros da sequência didática. 


\section{Quadro 1: Questão sociocientífica - O caso das sementes transgênicas.}

CASO DAS SEMENTES TRANSGÊNICAS

Imagine que seu pai é um agricultor que aprendeu a armazenar e plantar sementes de milho e hoje ele possui uma lavoura onde utiliza sementes naturais, que são guardadas durante um período e utilizadas em outras plantações. Além disso, o milho é vendido para a fabricação de massas de milho que são usadas por muitas pessoas para fazer cuscuz.

Um dia seu pai recebe uma visita de Paulo, seu velho amigo, que the oferece sementes transgênicas, e diz:

- Estou comprando e plantando sementes transgênicas e recomendo que você também use, pois irá aumentar sua produção de milho!

Seu pai responde:

- Não sei... Não conheço essas sementes, mas vou pensar...

Então mais tarde ele comenta com sua família sobre a oferta do seu amigo, e você diz:

- Pai, a professora irá falar sobre isso na aula amanhã, vou perguntar para ela.

No dia seguinte na sala de aula você pergunta:

- Professora, as sementes transgênicas são boas para a plantação?

E então uma de suas colegas responde:

- Na TV eles dizem que são boas, por conta do aumento da produção, mas eu acho que não é bom para nossa saúde no futuro.

A professora então responde:

- Além da saúde o uso dessas sementes também pode trazer consequências para o ambiente, por isso é melhor que seu pai analise bem essa proposta.

E então, qual conselho você daria para seu pai, usar ou não essas sementes? Explique o porquê da sua decisão.

\section{QUESTÕES NORTEADORAS}

1. Existe relação entre os alimentos transgênicos e o uso de agrotóxicos?

2. $\mathrm{O}$ consumo de alimentos transgênicos traz consequências?

3. $\bigcirc$ que você precisa saber sobre o uso das sementes transgênicas antes de usá-las?

4. Se o milho transgênico e o natural fossem do mesmo preço, qual você compraria? 
5. Quais os interesses para a produção dos alimentos transgênicos?

6. Você concorda com a produção dos alimentos transgênicos? Por que?

7. Quem são as pessoas beneficiadas com a produção dos alimentos transgênicos?

\section{OBJETIVOS CONCEITUAIS}

- Compreender conceitos principais como: biotecnologia, gene, transgênicos;

- Caracterizar o processo histórico e surgimento dos transgênicos;

- Conhecer o processo de produção dos transgênicos;

- $\quad$ Pontuar quais são os alimentos transgênicos produzidos no Brasil;

- Conhecer a legislação que regulamenta a produção, consumo e pesquisa sobre transgênicos (Lei de Biossegurança - Lei n. 11.105) e apresentar sobre rotulagem desses alimentos através do seguinte projeto de lei: (PL n 34/2015);

- Compreender através da cultura científica conceitos como: semente transgênica, polinização e fluxo gênico.

- Compreender quais as implicações sociais, ambientais e para a saúde humana resultantes do uso dos transgênicos;

- Relacionar o uso de sementes transgênicas com a redução da biodiversidade e uso de agrotóxicos;

- Entender a relação da ciência, da tecnologia e dos interesses econômicos na produção dos alimentos transgênicos;

- Compreender a influência dos transgênicos sobre o meio ambiente natural e suas consequências socioambientais.

\section{OBJETIVOS PROCEDIMENTAIS}

- Dialogar com a professora durante a aula.

- Identificar o símbolo dos alimentos transgênicos;

- Participar ativamente das discussões durante as aulas.

- Identificar, avaliar e argumentar sobre a produção dos transgênicos e os interesses científicos e tecnológicos em detrimento das questões ambientais.

\section{OBJETIVOS ATITUDINAIS}

- $\quad$ Posicionar-se de maneira crítica sobre o contexto histórico em que surgiram os transgênicos e qual o objetivo na época;

- Posicionar-se de maneira crítica sobre a importância econômica em 
detrimento das questões socioambientais.

- Posicionar-se de maneira crítica sobre a influência dos transgênicos na resistência das populações e suas consequências.

- Posicionar-se de maneira crítica sobre as modificações da legislação referente a rotulagem dos alimentos transgênicos.

- Respeitar as diferentes opiniões oriundas de diferentes contextos culturais;

- Trabalhar em equipe e valorizar a coletividade;

- Cooperar com o grupo durante a elaboração de argumentos;

Fonte: dados da pesquisa (2019).

\section{$1^{\circ}$ Encontro: $O$ processo histórico e produtivo dos transgênicos}

No primeiro encontro apresentamos a abordagem baseada em QSC que seria realizada durante algumas aulas, por meio de uma adaptação das etapas segundo Hodson (2011). E em seguida, dialogamos sobre necessidade do trabalho em grupo baseado no respeito das diferentes opiniões e cooperação com os colegas ao longo das aulas.

Após esse primeiro momento, o caso foi lido pela pesquisadora em voz alta para todos, apresentado a temática da sequência didática, posteriormente foi solicitado que os estudantes comentassem sobre as questões norteadoras, o que sabem sobre a temática e o que não sabem. A partir daí o diálogo foi mediado com base nas seguintes temáticas: definição e surgimento dos organismo transgênico, manipulação de genes, resistência das plantas após o uso de agrotóxicos. A habilidade de diálogo é primordial nessa etapa, para deixar os estudantes à vontade para expressarem suas opiniões sobre o tema. Aqui, segundo Baptista (2014), entendemos o diálogo no ensino de ciências como uma comunicação que permite a exposição de argumentos sobre a temática trabalhada na sala de aula.

Para finalizar esta aula os estudantes foram orientados a realizar uma pesquisa extraclasse sobre a legislação e implicações dos transgênicos, as vantagens e desvantagens do seu uso para serem discutidas na aula seguinte.

\section{$2^{\circ}$ Encontro: Os transgênicos e suas implicações.}


para que os estudantes percebessem a presença dos transgênicos nos produtos utilizados no cotidiano, mostrando alguns exemplos de alimentos transgênicos produzidos no Brasil, como a soja, o milho e alguns derivados, como óleo de cozinha, biscoitos, dentre outros.

Em seguida, foi retomada duas questões norteadoras, tais como: "O consumo de alimentos transgênicos traz consequências?"; "Existe relação entre os alimentos transgênicos e o uso de agrotóxicos?". A partir delas iniciamos o diálogo a respeito da existência da legislação e pontos mais importantes como, a produção, consumo e comercialização. No que tange a produção, discutimos sobre relação existente entre a produção dos transgênicos, produção de agrotóxicos e suas implicações socioambientais.

\section{$3^{\circ}$ Encontro: Tomada de decisão sobre caso das sementes.}

No último encontro os estudantes finalmente tomaram uma decisão diante da questão que finaliza o caso: "E então, qual conselho você daria para seu pai, usar ou não essas sementes? Explique o porquê da sua decisão. ". Em grupo, eles indicaram o uso ou não das sementes transgênicas elencando argumentos para chegar a essa conclusão. Eles foram orientados então a construir um pequeno texto que informe sua decisão discutindo os conhecimentos que foram utilizados na justificativa de suas decisões.

Os argumentos construídos por eles foram utilizados como forma de avaliação dos estudantes. Contudo, vale lembrar que não existe uma tomada de decisão certa ou errada, mas uma série de informações e conhecimentos relevantes para tomar determinada decisão. O que importará nessa sequência é que os estudantes envolvidos alcancem os objetivos conceituais, procedimentais e atitudinais, mesmo que porventura tomem decisões distintas da que um cientista e/ou professor tomaria. Certamente as necessidades e expectativas dos alunos podem considerar alguns elementos como mais prioritários do que outros, por exemplo, a condição econômica de cada um ou valores ecológicos. Ao professor cabe garantir que o estudante tome essa decisão de forma informada, que consiga buscar no conhecimento científico, o suporte para entender o problema que lhe atinge e que necessita de uma tomada de decisão. 


\section{RESULTADOS E DISCUSSÃO}

Neste item apresentamos os resultados organizados em dois quadros. O primeiro contendo as decisões dos grupos de estudantes em relação ao uso ou não de sementes transgênicas em uma plantação, e o segundo com seus respectivos níveis e estágios de letramento científico crítico alcançados por cada grupo. Percebemos no quadro 2 a similaridade entre as decisões dos grupos, primeiro porque todos optaram por não usar sementes transgênicas na plantação, e segundo porque compartilham da mesma justificativa argumentando sobre as consequências causadas pelos transgênicos para a saúde humana quanto para o meio ambiente de um modo geral.

\section{Quadro 2: Tomada de decisão dos grupos.}

\begin{tabular}{|l|l|}
\hline Grupos & Decisões \\
\hline $\mathbf{1}$ & $\begin{array}{l}\text { Não, porque iria prejudicar o solo e o ambiente pode ocasionar } \\
\text { doenças em nosso corpo. }\end{array}$ \\
\hline $\mathbf{2}$ & $\begin{array}{l}\text { Não, porque além de trazer danos futuros a nossa saúde e ao meio } \\
\text { ambiente, já era uma cultura de plantar sementes não } \\
\text { transgênicas. }\end{array}$ \\
\hline $\mathbf{3}$ & $\begin{array}{l}\text { Não, porque as sementes transgênicas causam danos ao os seres } \\
\text { vivos e a desnutrição do solo. }\end{array}$ \\
\hline $\mathbf{4}$ & $\begin{array}{l}\text { Não, pois prejudicaria nossa saúde de certa forma, acabaria } \\
\text { afetando o solo por conta dos agrotóxicos utilizados, assim como } \\
\text { alguns animais, entre outras coisas. }\end{array}$ \\
\hline
\end{tabular}

Fonte: dados da pesquisa (2019).

Analisamos os dados obtidos a partir da comparação entre as respostas dos estudantes, com base nos Níveis e Estágios de Letramento Científico Crítico propostos por Conrado (2017), modificada de Conrado; Nunes-Neto; El-Hani (2016); Conrado; Nunes-Neto (no prelo). A autora propõe parâmetros para avaliar o alcance de letramento científico crítico por meio de quatro estágios de zero a três para cada nível de letramento. O primeiro nível está relacionado ao reconhecimento de relações CTSA. No estágio zero não há percepção de conexões e conhecimentos sobre Ciência, Tecnologia, Sociedade e Ambiente. No estágio um há a percepção de benefícios da ciência e da tecnologia sobre 
sociedade e ambiente. No estágio dois percebe-se os impactos da ciência e da tecnologia sobre a sociedade e o ambiente. E no estágio três há o reconhecimento de que a ciência e tecnologia são culturalmente determinadas, indicando relações mútuas entre conhecimentos de Ciência, Tecnologia, Sociedade e Ambiente.

O segundo nível está relacionado ao reconhecimento da influência de interesses e do poder no desenvolvimento científico e tecnológico. No estágio zero percebese a neutralidade da ciência e da tecnologia. No estágio um há a percepção da influência de interesses de determinados grupos sociais no desenvolvimento científico e tecnológico. O estágio dois explicita que a influência do poder na ciência e na tecnologia pode gerar consequências negativas para indivíduos, sociedades e ambientes. E o estágio três reconhece que as atividades científicas e tecnológicas ocorrem sob interesses de particulares, em prol dos benefícios de alguns, à custa de outros (CONRADO, 2017). O nível três refere-se à capacidade para abordar criticamente controvérsias, explicitar valores, e para juízo ético. No estágio zero não aponta controvérsias e valores distintos envolvidos nas relações entre CTSA e na QSC. No estágio um verifica-se a presença de diferentes valores e pontos de vista envolvidos na QSC. No estágio dois há questionamentos sobre juízos, valores e decisões próprias e dos outros. E no estágio três analisa criticamente contradições e coerência entre valores e condutas para formular sua própria opinião e juízo moral, justificados de modo fundamentado (CONRADO, 2017).

E por último, o nível quatro está relacionado a capacidade para tomada de decisão e para ações sociopolíticas. No estágio zero não há tomada de decisão sobre QSC. No estágio um há tomada de decisão desconsiderando consequências, prós e contras de ações e propostas. No estágio dois há tomada de decisões considerando implicações, prós e contras e efeitos de ações e propostas, e por último no estágio três há tomada de decisões socioambientalmente responsáveis e parte para a ação (CONRADO, 2017).

Com base nesses parâmetros analisamos as tomadas de decisões de cada grupo e identificamos os níveis e estágios de letramento científico crítico que cada um conseguiu alcançar, como é possível observar no quadro abaixo: 


\section{Quadro 3: Níveis e estágios alcançados por cada grupo.}

\begin{tabular}{|l|l|l|l|l|}
\hline Grupos & Nível 1 & Nível 2 & Nível 3 & Nível 4 \\
\hline $\mathbf{1}$ & Estágio 2 & - & - & Estágio 2 \\
\hline $\mathbf{2}$ & Estágio 2 & - & - & Estágio 2 \\
\hline $\mathbf{3}$ & Estágio 2 & - & - & Estágio 2 \\
\hline $\mathbf{4}$ & Estágio 2 & - & - & Estágio 2 \\
\hline
\end{tabular}

Fonte: dados da pesquisa (2019).

Dada as suas respostas, percebemos que os grupos alcançaram os níveis 1 e 4, sendo o estágio 2 nestes dois níveis. O nível 1 porque eles perceberam que a ciência e a tecnologia estão envolvidas no processo de desenvolvimento e produção dos transgênicos. E o estágio 2 porque indicaram que o plantio e o consumo deles resultam em efeitos negativos tanto para a saúde humana quanto para o meio ambiente. Cabe destacar que esta foi uma justificativa utilizada por todos os grupos para amparar suas decisões. Outro nível alcançado pelos estudantes foi o nível 4 porque eles conseguiram tomar uma decisão, o que por si já indica o seu alcance. E o estágio 2 deste nível porque as respostas indicam uma posição negativa em relação ao uso de sementes transgênicas justificada pela afirmação sobre possíveis consequências que esse plantio pode causar.

As decisões dos estudantes corroboram com a ideia de Pinazza e Alimandro (1998) quando eles já afirmavam que existe a possibilidade de riscos associados aos OGM, o que mostra que os estudantes compreenderam a relação entre a interferência da ciência nas relações estabelecidas entre sociedade e a natureza, e essa compreensão é importante para a formação de cidadãos críticos. Apesar desse achado, inferimos que as respostas estão amparadas em argumentos pouco explicativos acerca das implicações socioambientais relacionadas ao uso dos transgênicos, pois os estudantes poderiam fundamentá-la de maneira mais explicativa, apresentando, especificamente exemplos de tais consequências que foram discutidos durante as aulas.

No entanto, não foi o que aconteceu, e a unanimidade das decisões negativas ao uso de sementes transgênicas pautadas em justificativas muito resumidas é uma indicação da dificuldade de argumentação para tomada de decisão, que pode estar relacionada a disponibilidade de tempo para a aplicação de uma sequência que aborde questões controversas. Para Weston (1996, p. 2) "argumentar não é 
apenas a afirmação de determinado ponto de vista nem uma discussão. Os argumentos são tentativas de sustentar certos pontos de vista com razões", a argumentação consiste no uso de razões que explicam e defendem uma determinada conclusão. O autor também afirma que quando os estudantes precisam apresentar uma escolha ou opinião sobre determinado assunto é comum que eles apresentem afirmações sem razões que expliquem e reforcem a defesa de seus pontos de vista. E isso pode acontecer porque os assuntos trabalhados nas escolas geralmente são incontroversos e por isso eles não estão acostumados a questioná-los e consequentemente não elaboram argumentos. Ou pela maneira pela qual geralmente ocorre a prática docente, com o ensino pautado no ideal de estudante como observador passivo que não questiona o professor e nem é incentivado por este a ação de questionar e expor suas opiniões.

Apesar de apresentarmos nesse estudo uma temática controversa para a ciência, a dificuldade argumentativa esteve presente entre os estudantes que participaram da nossa pesquisa, ressaltamos também que houve motivação para que os estudantes apresentassem suas ideias, porém essas falas não foram problematizadas a ponto de provocar a argumentação. Os estudantes apenas falavam e a pesquisadora seguiu com a aula. Consideramos esse fato como sendo ruim para o diálogo, afinal, o diálogo não é apenas exposição de conhecimentos, mas também dos seus significados. Isto ocorreu pelo fato de que a pesquisadora estava preocupada com o seu tempo de intervenção na sala de aula, pois a professora da turma precisava seguir com suas atividades. Dito isso, podemos citar as principais dificuldades vivenciadas pela pesquisadora, tais quais: o tempo para aplicação da sequência, a falta de experiência profissional que influenciou da dificuldade em mediar um diálogo com os estudantes, pois essa é uma habilidade complexa para o professor diante da cultura escolar que reforça a passividade dos estudantes ainda mais para aqueles que estão no processo de formação inicial. Apesar disso, o fato de que os grupos compreenderam que existe uma relação entre os transgênicos e implicações socioambientais é o início do exercício da criticidade que pode auxiliar em possíveis decisões que possam tomar futuramente. Como bem indica Chassot (2003), aquele que compreende o conhecimento científico e tecnológico e os utiliza tem a possibilidade de ampliar o seu desenvolvimento em sua vida diária, de modo que isto contribui para a resolução de problemas. Desse modo, apesar das limitações, a compreensão dos estudantes 
foi significativa pelo fato da associação dos conhecimentos que eles já possuíam sobre a agricultura com os conhecimentos científicos dialogados nas aulas. O que Ihes possibilitará utilizar esse conhecimento científico em seu contexto sociocultural em situações em que seja necessário.

Por fim, como bem afirma Soares (2009), o letramento científico acontece quando o estudante sabe utilizar o conhecimento científico no âmbito social. E esse é justamente o tipo de ensino que almejamos, aquele que possibilita aos estudantes enxergarem sentido em tudo aquilo que é abordado em sala de aula e que de alguma maneira eles possam usar os conhecimentos ministrados para auxiliar em determinados momentos de sua vida. E, na sala de aula isso é possível através do diálogo, que segundo Baptista (2010) acontece quando ocorre mediação entre os conhecimentos prévios dos estudantes e o conhecimento científico nos momentos de ensino possibilitando aos estudantes saber utilizá-lo para solucionar problemáticas provenientes do local onde vivem.

\section{CONSIDERAÇÕES FINAIS}

Nossas análises indicam que ao final da aplicação da sequência didática os estudantes alcançaram determinados níveis e estágios de letramento científico crítico que evidenciam alguns aspectos como a percepção da influência entre a tecnologia e ciência para com o ambiente, isso porque eles conseguiram utilizar a criticidade através da escolha de não usar sementes transgênicas, evidenciando como principais justificativas a existência de consequências socioambientais associadas aos transgênicos, como as sementes crioulas, e, a relação entre agrotóxicos e transgênicos e suas consequências. No entanto, suas decisões foram muito resumidas, carentes de argumentação mais fundamentadas em explicações científicas, o que possivelmente está relacionado a sequência didática devido ao tempo disponibilizado atrelado aos estudantes não estarem habituados a trabalhar com sequências didáticas e QSC.

Sabendo disso, ressaltamos que houve algumas limitações na pesquisa, podendo citar a quantidade de encontros reduzidos para a abordagem de temática controversa, visto que é uma metodologia que ainda não está totalmente inserida nas práticas pedagógicas da educação dessa comunidade tradicional e por isso se faz necessário mais tempo para explicar a dinâmica da abordagem de temáticas controversas e que incluam uma abordagem CTSA e um caso de QSC 
para que os estudantes a compreendam de maneira mais ampla. E a partir daí possa facilitar a leitura, reflexão e argumentação, conjunto este que não é tão fácil considerando que os estudantes não estão acostumados a trabalhar dessa maneira em sala de aula.

Essas percepções decorridas após a aplicação dessa sequência didática permitiram nossas reflexões sobre o que pode ser melhorado no que tange a sua abordagem com intuito de ampliarmos os níveis e estágios de letramento científico alcançado pelos estudantes. E essas reflexões abrem margem para propormos ajustes em trabalhos futuros visando outra aplicação e que contribua no processo de ensino e aprendizagem voltado para a criticidade.

\section{REFERÊNCIAS}

BAPTISTA, G. C. S. A Contribuição da etnobiologia para o ensino e a aprendizagem de Ciências: estudo de caso em uma escola pública do Estado da Bahia. 2007.

BAPTISTA, G. C. S. Importância da demarcação de saberes no ensino de Ciências para sociedades tradicionais. Ciência \& Educação, 16(3), 679-694, 2010.

CERQUEIRA, R. J., ANDENA, S. R. Levantamento da fauna de vespas (Hymenoptera, Vespidae, Polistinae) na região do Arraial do Retiro, distrito de Coração de Maria, Bahia. Anais Seminário de Iniciação Científica, n. 21, 2017.

CHASSOT, A. Alfabetização científica: uma possibilidade para a inclusão social. Revista brasileira de educação, v. 22, n. 1, p. 89-100, 2003.

CONRADO, D. M. Questões sociocientíficas na Educação CTSA: contribuições de um modelo teórico para o letramento científico crítico. 2017.

CONRADO, D. M., EL-HANI. Questões sociocientíficas e dimensões conceituais, procedimentais e atitudinais dos conteúdos no ensino de ciências. In: CONRADO, D. M, NUNES-NETO, N. Questões sociocientificas: fundamentos, propostas de ensino e perspectivas para ações sociopolíticas. Salvador: EDUFBA, 2018, 570 p.

CRESWELL, J. W. Projeto de pesquisa: métodos qualitativo, quantitativo e misto. $3^{a}$ ed. Porto Alegre: ArtMed, 2010.

DIEGUES, A. C. e ARRUDA, R. S. V. (Orgs). Saberes tradicionais e biodiversidade no Brasil. Brasília: Ministério do Meio Ambiente; São Paulo: USP, 2001.

FREIRE, P. Pedagogia do oprimido, 17ª ed. Rio de Janeiro, Paz e Terra, 1987.

GUILHERME, L. R. G. Fundamentos da Análise de risco: Conceitos em análise de risco ecológico e para a saúde humana. Biotecnologia Ciência \& Desenvolvimento, n. 34, p. 10-12, 1 fev. 2005.

HODSON, D. Going beyond STS: Towards a Curriculum for Sociopolitical Action. Science Education Review, v. 3, n. 1, p. 2-7, 2004. 
HODSON, D. Looking to the Future: Building a Curriculum for Social Activism. Auckland: Sense, 2011.

HODSON, D. Realçando o papel da ética e da política na educação científica: Algumas considerações teóricas e práticas sobre questões sociocientíficas. In: CONRADO, D. M. e NUNES-NETO, N. Questōes sociocientíficas: fundamentos, propostas de ensino e perspectivas para ações sociopolíticas (Org.). Salvador: EDUFBA, 2018. $570 \mathrm{p}$.

LOPES, C. V. Al.; ALBUQUERQUE, G. S. C. de. Agrotóxicos e seus impactos na saúde humana e ambiental: uma revisão sistemática. Saúde em Debate, v. 42, p. 518-534, 2018.

PAIVA, A. S. et al., Validação de uma sequência didática sobre mitose e câncer articulada com discussões éticas e ações sociopolíticas. VIII Encontro Regional de Ensino de Biologia RJ/ES - 11 a 13 de setembro de 2017. Rio de Janeiro, RJ. UNIRIO - UFRJ - IBC.

PEDRANCINI, V. D., CORAZZA-NUNES, M. J., GALUCH, M. T. B., \& Nunes, W. M. C. (2008). Saber científico e conhecimento espontâneo: Opiniões de alunos do ensino Médio sobre transgênicos. Ciência \& Educação, 14(1), 135-146.

PÉREZ, L. F. M. Questões sociocientíficas na prática docente: ideologia, autonomia e formação de professores. São Paulo: Editora Unesp, 2012.

PINAZZA, L. A.; ALIMANDRO, R. A segunda revolução verde. AgroANALYSIS, v. 18, n. 10, p. 37-43, 1998.

SANTOS, W. L. P. Educação científica humanística em uma perspectiva freireana: resgatando a função do ensino de CTS. Alexandria Revista de Educação em Ciência e Tecnologia, v.1, n.1, p. 109-131, mar. 2008.

SANTOS, W. L. P. Educação científica na perspectiva de letramento como prática social: funções, princípios e desafios, Revista Brasileira de Educação, v. 12, n. 36, p. 474-550, 2007.

SILVA, L. F.; CARVALHO, L. M. A temática ambiental e o processo educativo: o ensino de física a partir de temas controversos. Ciência \& Ensino, Campinas, v. 1, n. esp., nov. 2007.

SILVA, M. L. S.; BAPTISTA, G. C. S. Conhecimento tradicional como instrumento para dinamização do currículo e ensino de ciências. Revista Gaia Scientia, vol. 12(4): 90104, 2018.

SOARES, M. Letramento: um tema em três gêneros. $3^{a}$ ed. Belo Horizonte: Autêntica editora, 2009. 128p.

SOCOLOSKI, T. S. Letramento científico crítico e gênero notícia de PC: análise de atividades didáticas de leitura em língua inglesa. 201 1. Dissertação (Mestrado em Letras) - Universidade Federal de Santa Maria, 2011. 
SOUZA, A. F.; FARIAS, G. B. Percepção do conhecimento dos alunos do ensino médio sobre transgênicos: concepções que influenciam na tomada de decisões. Experiências em Ensino de Ciências - V6(1), pp. 21-32, 2011.

VIEIRA, C. T.; VIEIRA, R. M. (2014). Construindo Práticas Didático Pedagógicas Promotoras da Literacia Científica e do Pensamento Crítico. Documentos de Trabajo e Iberciencia. N. 2. Madrid: Iberciencia.

WESTON, A.; MURCHO, D.; BRANQUINHO, J. A arte de argumentar. Lisboa: Gradiva, 1996.

ZABALA, A. A prática educativa: como ensinar. Porto Alegre: ArtMed, 1998. 